\title{
THE RELATIVE IMPORTANCE TO LIFE OF CORTEX AND MEDULLA OF THE ADRENAL GLANDS
}

\author{
B. A. HOUSSAY AND J. T. LEWIS \\ From the Institute of Physiology, Faculty of Medicine, Buenos Aires
}

Received for publication January 27, 1923

Loss of both adrenals provokes death in a few hours in nearly all species. In dogs within 1 to 3 days (average, 26 hours) according to our own experiments. In man alterations of these glands occasion death in a short time (Sergent-Bernard's syndrome) or else bring about Addison's disease, of longer duration but not less fatal. The suprarenals must therefore be considered as organs essential to life. But as they are formed by two different tissues, cortical and medullary, the question arises as to which of them plays a principal part.

Some authors maintain that the medulla is the vital tissue, others that it is the cortex. Pende believes that both are necessary to life. We will examine the evidence brought to support these different opinions and afterwards discuss them with the help of our own experiments on this subject.

Predominance of medulla. This tissue secretes a substance of powerful pharmacological activity, adrenalin; it is therefore natural to presume that it is of great importance, especially if we consider that the functions of the cortex have not yet been clearly established.

A. and H. Cristiani (1) observed that extirpation of both adrenals provokes death in rats, and that these animals survive if extirpation is incomplete, provided that in the part left behind, medullary tissue is found in good condition. They also observed that suprarenal grafts are unable to maintain lifein adrenalectomized rats, although only the medul. lary tissue degenerates, the cortex being found in excellent condition. This evidence led them to believe that the medulla is essential to life.

Vassale and Zanfrognini (2) removed all the medullary tissue leaving only the cortex in cats and rabbits and found that this operation is as fatal as double adrenalectomy. Vassale (3) claims that extirpation of one adrenal and the abdominal paraganglia is always followed by death. 
Levi della Vida (4) has endeavored to destroy both tissues separately by means of cytotoxic sera. When a serum that has been prepared by injecting medulla into dogs or ducks, is administered to a guinea pig, the animal dies, great alterations being found in both adrenals, but only in the medulla, the cortex remaining almost intact. Serum prepared with cortex is almost harmless; it brings about only slight alterations.

Predorninance of cortex. Biedl (5) has brought out important evidence on this point. In dogs incomplete adrenal extirpation permits survival when an eighth of the adrenal tissue is left behind, provided that this portion consists of cortex. If all the cortex is removed, leaving the medulla as intact as possible, death occurs as after total adrenalectomy.

In Elasmobranchs both tissues are found separated. The cortex forms Balfour's inter-renal body and the medullary tissue is disseminated in numerous small bodies. Extirpation of the inter-renal body provokes death, although all the chromaphil tissue remains.

Swale Vincent (6) and Pettit (7) repeated these experiments in eels, obtaining different results. Later Giacomini (8) described a cranial portion of the cortical tissue in these animals and so explained these last authors' results; they had made only incomplete extirpation of the inter-renal tissue, therefore their animals survived.

Pende (9) has proved that denervation of the adrenals is followed by atrophy of the medulla. Stewart and Rogoff (10) removed one adrenal and cut all nerves going to the other in cats, dogs, rabbits and monkeys. Five weeks later no adrenalin could be found in the blood taken from the capsular vein although their test method was sensitive up to 1:1000 millions. These animals had no abnormal symptoms, so that we can deduce that adrenalin is not indispensable to life and to the normal functioning of the organism.

Wheeler and Vincent (11) completely removed the left adrenal, and amputated half the right gland, cauterizing its medulla. Three weeks or a month later the remaining gland tissue was extirpated, stained with Müller's fluid and examined for the presence of medullary tissue. A total of 32 dogs, 24 cats and 4 rabbits were operated. In all cases where death was due to operation and not to accident, such as loss of blood, anesthesia, etc., extensive damage to the cortex had been done. In several instances, where no symptoms had been observed, all or practically all the medulla had been removed. 
Necessity of both portions. Pende (12) believes that the compound organ is necessary to life. He has observed that grafts maintain life in cats after adrenalectomy for a longer time when both tissues live in the graft. These experiments are not convincing because it is not possible to arrive at a definite conclusion whether the association of cortex and medulla is or is not always more efficient in grafts than the presence of one only of the tissues. Pende supposes the existence of certain functions realized by this association, but up to the present nobody has been able to establish in what they consist.

Experiments. We have used dogs in our experiments for several reasons: 1, Total adrenalectomy always provokes death in a short lapse of time (from 1 to 3 days, 26 hours mean); 2 , it is possible to remove all the medulla leaving the cortex behind; 3 , their size makes the operation easy and permits divers physiological observations.

Following our technic it is possible to obtain survival in the great majority of cases, after total extirpation of the adrenal medulla.

First the left adrenal medulla is removed. For this the left suprarenal is exposed through a dorsal incision, the vein is separated and both ends of the gland are dissected, cutting the splanchnic nerve, but leaving a good vascular pedicle on the internal side. This pedicle is taken up with a curved clamp, so as to prevent bleeding and to hold the gland during the rest of the operation. The gland is then opened lengthwise, with a sharp Gillette blade, as if it were a book. Medulla and cortex can be easily differentiated, and all the medulla removed with a spoon. It is convenient to remove also a part of the cortex so as not to leave any chromophil tissue behind. The gland is sewed up with catgut and the body wall closed.

A week or ten days later the right adrenal is removed.

In a first series 16 dogs were operated in this way. Three (nos. 4, 7 and 9) died within 48 hours, with symptoms of total adrenalectomy. Severe damage had been done to the cortex. One (no. 1) ran away after 7 days in excellent health. Another (no. 10) did the same thing 4 days after operation, without having had symptoms. Three were allowed to survive a long time; in two the remaining cortex was removed 217 and 232 days after the second operation (nos. 8 and 14); they died in 24 and 26 hours with symptoms of double adrenalectomy. The remaining eight were used in different experiments; 3 (nos. 3, 2 and 6) in the first week after operation, 1 (no. 11) in the second week, 3 (nos. 13, 15, and 16) in the third week, 1 (no. 12) a month after the second operation. 
All the animals that survived had no abnormal symptoms; once the skin had healed and the hair grown, no difference could be found from normal dogs.

In five of these the pancreas was removed according to Witzel's technic, somewhat modified. Two survived 8 and 3 days, the sugar in the blood rising after operation from 0.7 per cent to 4 per cent and from 0.8 per cent to 3.63 per cent (Folin and Wu's method). Sugar in the urine reached 100 per cent (Fehling's method). In the second dog, a

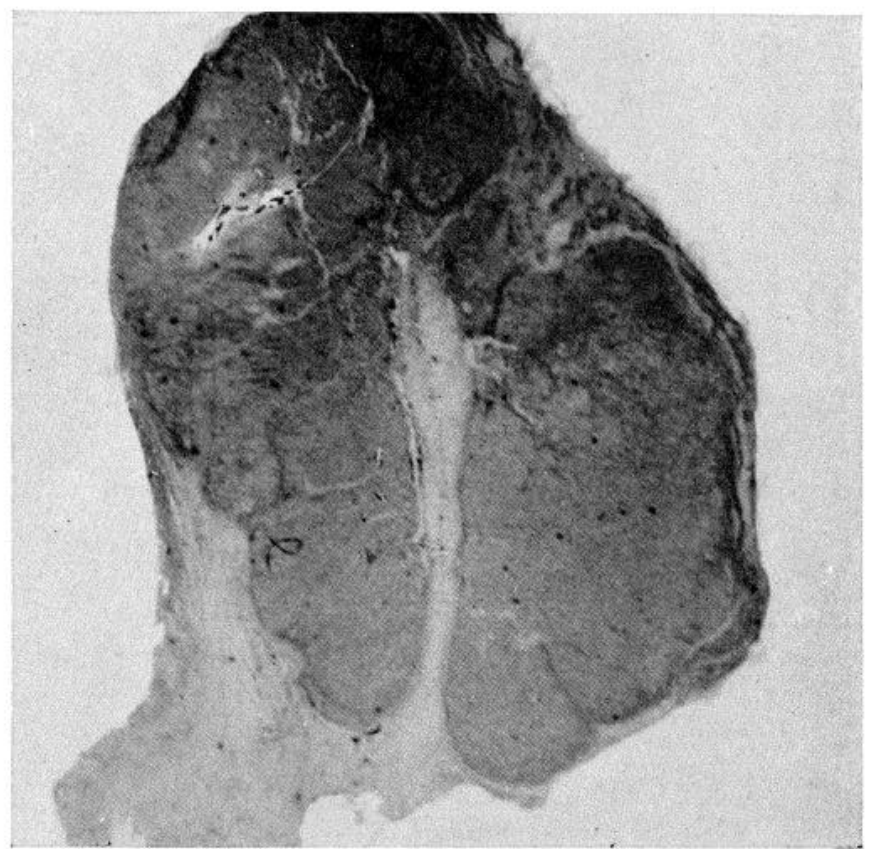

Fig. 1. Left suprarenal gland, after operation. In the center scar left by surgical wound. Round it cortical tissue. No chromaphil cells are to be found.

small portion ( $100 \mu \times 100 \mu \times 1 \mathrm{~mm}$.) of medulla was found; in the first dog not the slightest residue of chromaphil tissue was present. The 3 other dogs maintained, or slightly lowered their blood sugar. In one a small part of the pancreas was found. The other two died 6 and 24 hours after operation, certain surgical difficulties had been found, and shock had been produced.

In seven dogs, among those that had survived longest, the left adrenal was stained and searched for chromophil tissue, only in the one 
already mentioned was medullary tissue found; the others had not the slightest portion left behind. The cortex was in good state, with numerous vacuolated cells (spongiocytes). A central scar remained, from which tracts of sclerosis branched out.

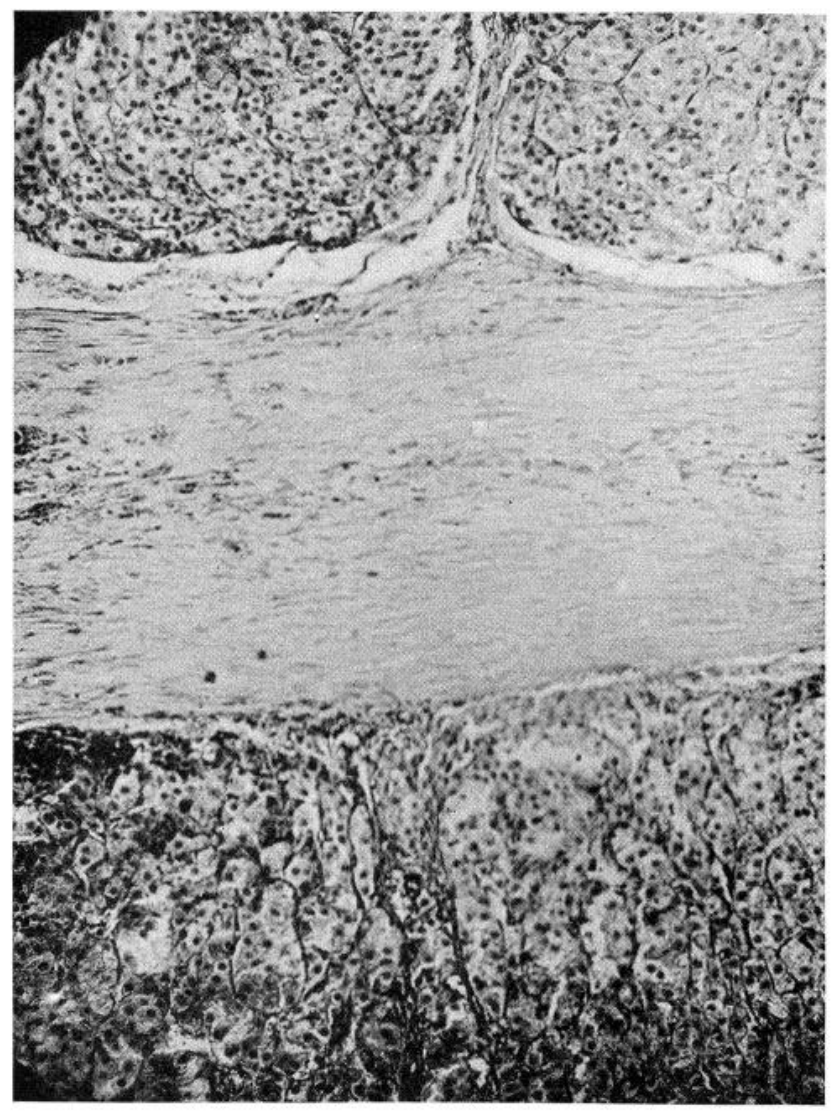

Fig. 2. Left adrenal gland after operation. Cortical tissue in direct contact with central scar. No chromaphil cells.

A second series of 9 dogs was operated in the same way as described, four of which died on the day following the second operation; the other five survived and a month after were in excellent health.

Two were depressed during a short time after the operation, later this symptom disappeared, and like the rest they ran about actively, were 
affectionate and in all ways behaved as normal dogs. Weight increased in two, remained stationary in two, was lowered in one. Pulse-rate, breathing and temperature were found normal. Some had infections in the surgical wounds, but healed as is usual. In none was found abnormal pigmentation of skin or mucosae. Hair was in excellent state.

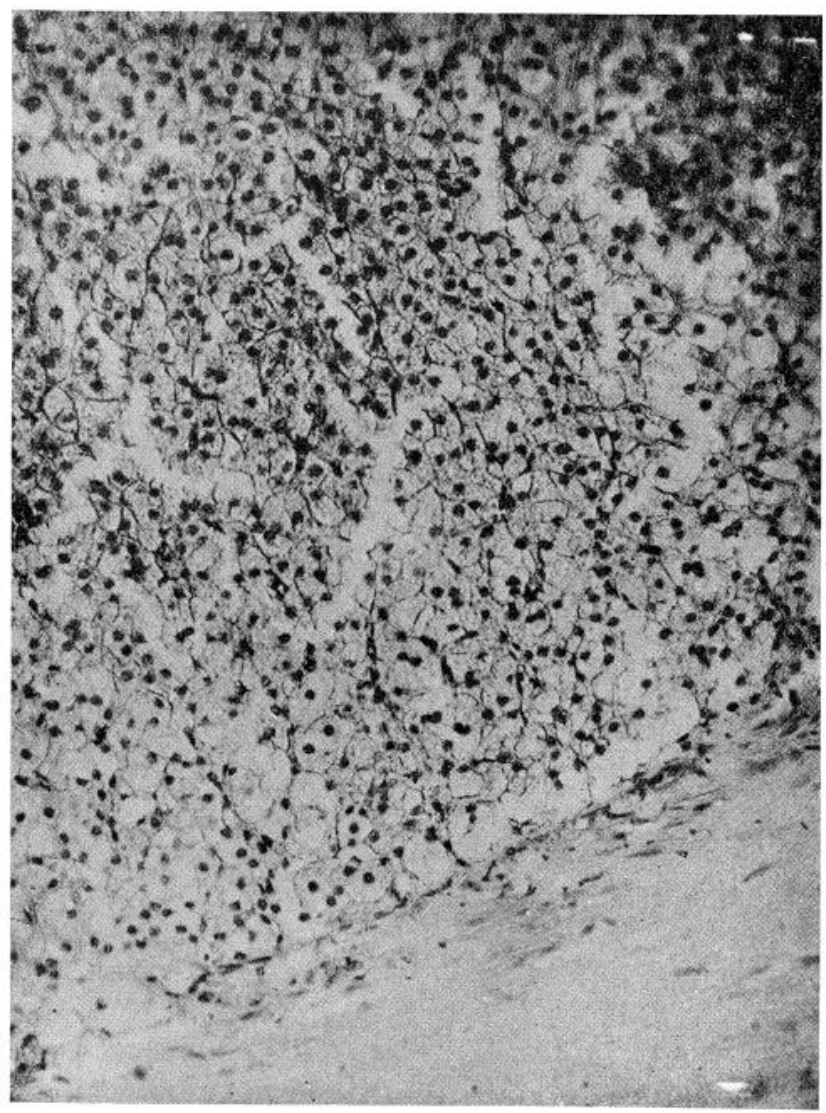

Fig. 3. Cortex cells on boundary of central scar. Typical spongiocytic aspect.

A month after the second operation blood pressure was measured in the femoral artery and adrenalin or pituitary extract injected. Blood pressure was found normal $(115 \mathrm{~mm}$. Hg. mean) and similar to that found in controls. Intravenous injection of adrenalin (Parke-Davis) $1: 10,000,000,1: 1,000,000,1: 100,000$, and $1: 50,000$ had the same effect in the 5 operated dogs as in controls. 
Injection of $0.5 \mathrm{cc}$. "Infundin" (20 per cent pituitary extract) in the jugular vein produced the same effect as in controls.

Application to the eye of 1:100 solution of cocain chlorhydrate, 1:200 atropin sulphate and 1:1000 adrenalin produces mydriasis of same duration and degree as in normal animals.

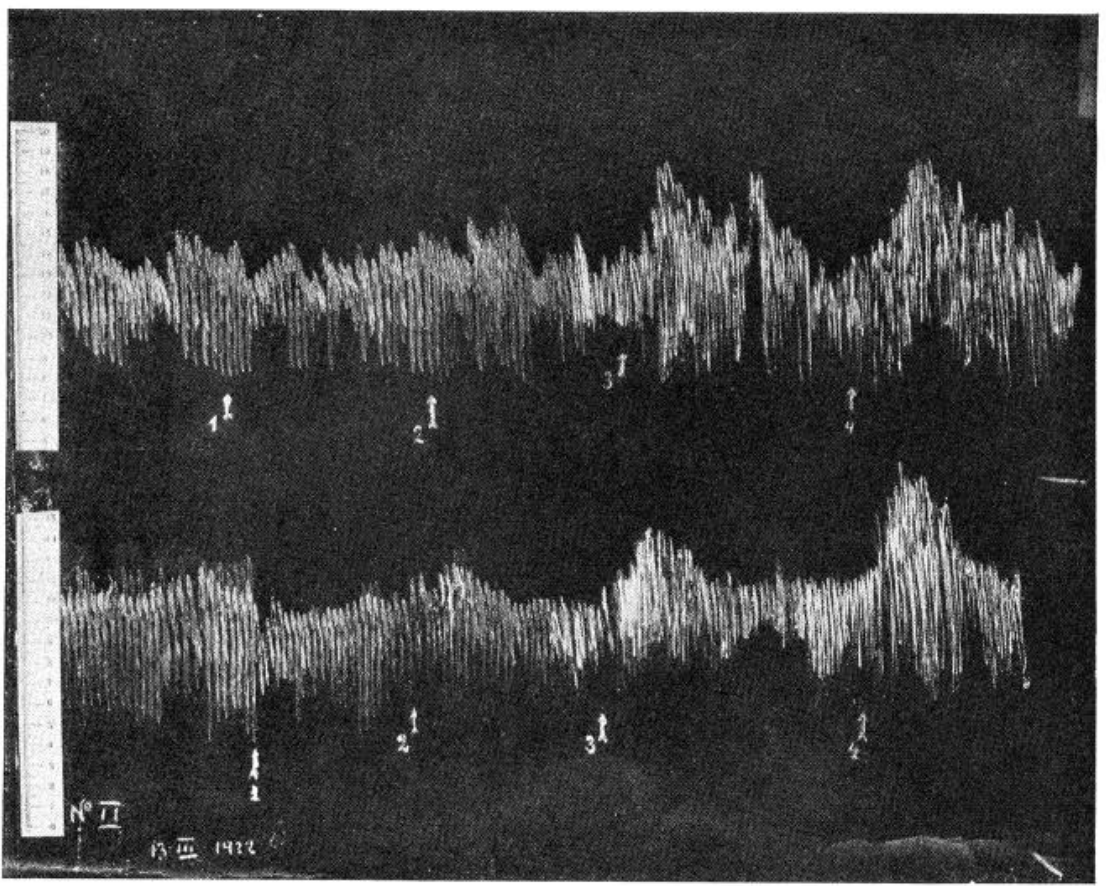

Fig. 4. Blood-pressure curve. 1, Injection 1 cc. adrenalin $1: 10,000,000 ; 2.1 \mathrm{cc}$. adrenalin $1: 1,000,000 ; 3,1$ cc. adrenalin $1: 100,000 ; 4,1$ cc. adrenalin 1:50,000.

Blood analysis (Folin and Wu's method) revealed normal quantities of

\begin{tabular}{l|l|l|l|l}
\hline Glucose per $100 \mathrm{cc} \ldots \ldots \ldots \ldots \ldots \ldots \ldots \ldots$ & 0.123 & 0.132 & 0.11 & 0.098 \\
Non-proteid N. per $100 \mathrm{cc} \ldots \ldots \ldots \ldots \ldots \ldots$ & 0.027 & 0.04 & 0.03 & 0.028 \\
Urea per $100 \mathrm{cc} \ldots \ldots \ldots \ldots \ldots \ldots \ldots \ldots \ldots$ & 0.012 & 0.018 & 0.015 & 0.012 \\
Sodium chloride per $100 \mathrm{cc} \ldots \ldots \ldots \ldots \ldots$ & 0.435 & 0.44 & 0.445 & 0.438 \\
\hline
\end{tabular}

Two had gaseous gangrene in wounds made for blood-pressure estimation, two bit through ligatures during the night and died of hemorrhage, the other was killed. Necropsy revealed nothing abnormal. 
Accessory glands were not found. The right adrenal had been totally removed. The left was stained and no chromophil tissue could be found. Its centre was occupied by a scar. Cortex cells had a typical spongiocytic aspect.

Discussion. Our experiments lead to the same conclusions as Biedl's and Wheeler and Vincent's, but the constancy of results obtained when

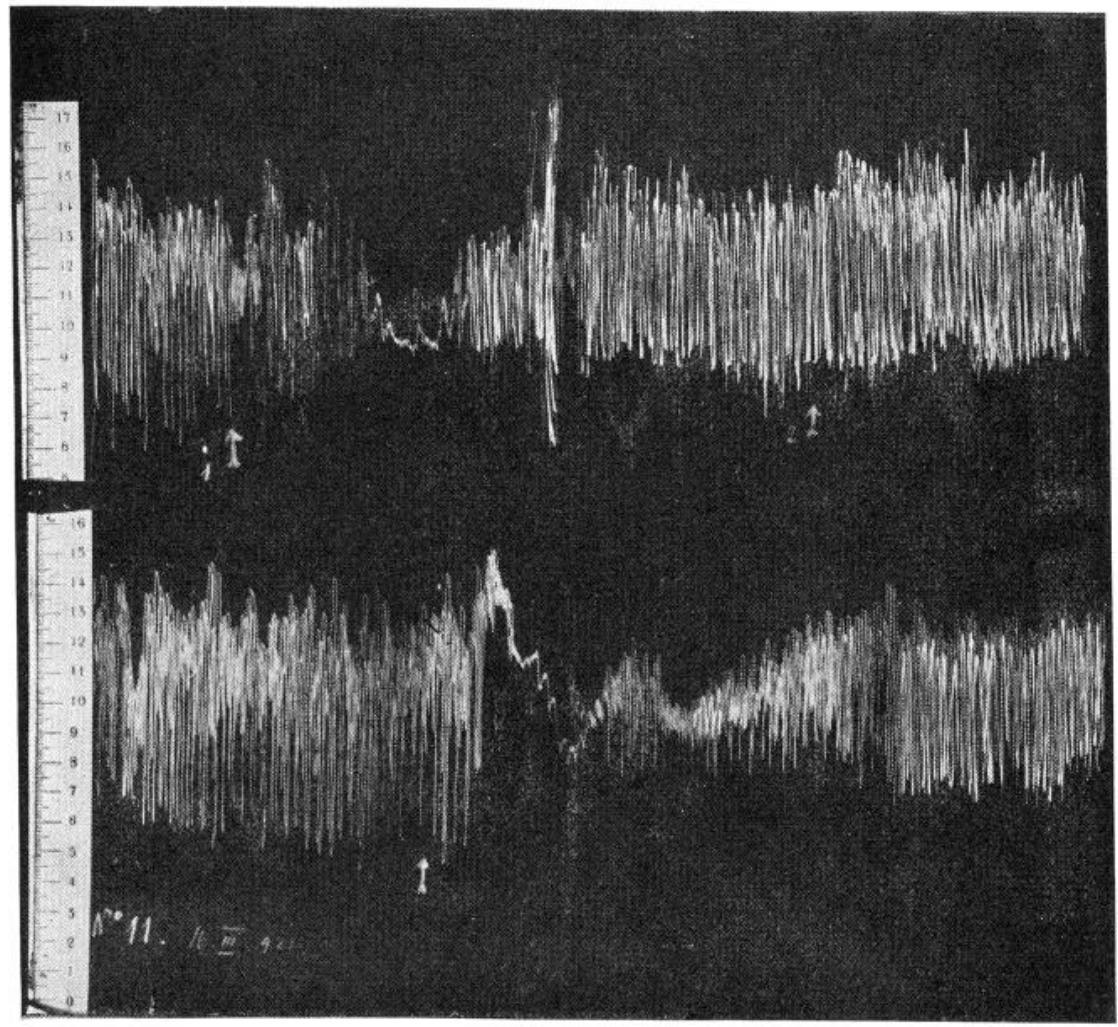

Fig. 5. Blood-pressure curve. Injection of 0.5 "Infundin" (20 per cent pituitary extract).

following our technic and the number of our experiments remove all doubts that may have remained.

Apparently contradictory evidence obtained by other authors can be explained by analyzing their experiments.

Cristiani's work can not be taken into account, as rats normally survive double adrenalectomy- 60 per cent to 80 per cent according to our experiments. 
Vassale and Zanfrognini possibly did severe damage to the cortex as happened in some of our own experiments. The fatal results of removal of one adrenal and abdominal paraganglia must be explained by some fault in technic as it is commonly known that one adrenal is amply sufficient to maintain life. Accessory chromophil tissue though abundant in dogs is not of great importance, quantitatively considered. Swale Vincent remarks that though in this species it is more abundant than in others double adrenalectomy is always fatal. On the other hand the accessory adrenals of rats, a species which survives double adrenalectomy, are made up of cortical tissue (Wiesel, 13).

Death brought about by injection of cytotoxic serums as in Levi della Vida's experiments, can not be allotted exclusively to specific alterations of a determined tissue, these serums contain heterogenetic antibodies, especially hemolysins (Abbot, 14), that are by no means harmless.

\section{SUMMARY}

The following facts are definitely established: 1, Double adrenalectomy is fatal in most species, amongst them the dog. 2, Removal of all chromophil tissue contained in these glands is perfectly harmless. 3, Fxtirpation of inter-renal body (equivalent of cortex in Elasmobranchs) is followed by death. We may therefore conclude, 1, The cortex is indispensable to life; it maintains its vital functions without the cooperation of the medulla. 2, The chromophil tissue of the suprarenals is not necessary to life or to normal functions.

This does not mean that chromophil tissue is not indispensable to life. In our experiments only a part of this tissue is removed, and it must be remembered that relatively a greater portion of medullary tissue than of cortical tissue remains in the body after adrenalectomy. If chromophil tissue has vital functions, the extra-capsular portion is sufficient to maintain them, but up to now we have no evidence that these vital functions exist.

\section{CONCLUSIONS}

1. Dogs survive extirpation of all chromophil tissue contained in the adrenals, when the remaining cortex is in good state.

2. If the remaining cortex is removed, animals die as after double adrenalectomy.

3. Dogs without the adrenal medulla maintain their functions normally. Weight is not lost. Body tempcrature, pulse rate, blood pressure, breathing and the chemical composition of blood are normal. 
4. No abnormal pigmentation or asthenia is observed.

5. Sympathetic irritability, as shown by injection of adrenalin or by pupillary reaction toward cocain, adrenalin and atropin, is normal.

6. The blood-pressure response to injection of pituitrin is normal.

7. Pancreatic diabetes can be established without secretion of adrenalin.

\section{BIBLIOGRAPHY}

(1) Christiani and Christiani: Compt. rend. Soc. Biol, 1902, liv, 710; Journ. de Physiol. et Path. Gén., 1902, iv, 837, 982.

(2) Vassale and Zanfrognini: Riforma Med., 1902, xviii, 316; Arch. Ital. de Biol., 1902, xxxviii, 175.

(3) Vassale: Arch. Ital. de Biol., 1905, xliii, 256.

(4) Levi della Vida: Lo Sperimentale, 1904, lviii, 919.

(5) BIEDL: Innere Sekretion, 1913.

(6) Vincent: Ergeb. d. Physiol., 1910.

(7) Pettit: cit. Biedl.

(8) Giacomini: cit. Biedl.

(9) Pende: Policlinico, 1903, x, 1793.

(10) Stewart and Rogoff: Journ. Pharm. Exper. Therap., 1917, x, 1; This Journal, 1919, xlviii, 397.

(11) Wheeler and Vincent: Trans. Royal Soc. Canada, 1917, xi, 125.

(12) Pende: Endocrinologia, 1920.

(13) Wiesel: Wien. Klin. Wochenschr. 1898, 443.

(14) Аввот: Centralbl. f. Bakt. (Orig. Abt.), 1913, xxiv, 696. 